\title{
Retail Power Market Competition with Endogenous Entry Decision-An Auction Data Analysis
}

\author{
By
}

Nobuhiro Hosoe

Shingo Takagi

April 2011

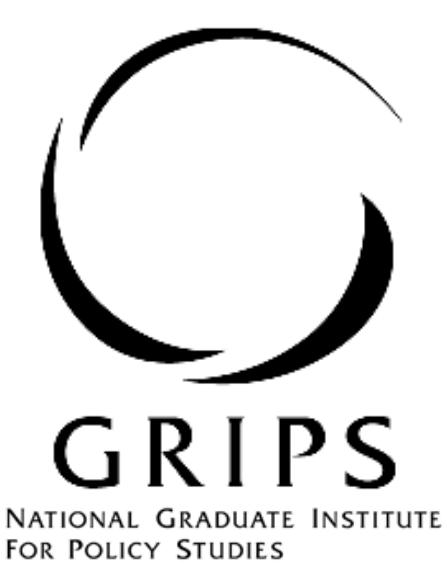

National Graduate Institute for Policy Studies

7-22-1 Roppongi, Minato-ku,

Tokyo, Japan 106-8677 


\title{
Retail Power Market Competition with Endogenous Entry
}

\section{Decision-An Auction Data Analysis}

April 7, 2011

Nobuhiro Hosoe

Shingo Takagi ${ }^{\dagger}$

\begin{abstract}
Deregulation in the electric power industry has been aimed at promoting competition and thereby enhancing the industry's efficiency. We use the auction data of public power procurements to study the impact of the reform on the retail power market in Japan. We quantify this impact by measuring a decline in power charges, controlling for the endogeneity bias caused by the entrants' bid-submission decisions. Our results suggest that power charges would decline by about $0.48 \mathrm{yen} / \mathrm{kWh}$ on average when two or more providers bid at an auction.
\end{abstract}

Keywords: electric power industry, auction data, public procurement, sample selection bias JEL Classification: L94(electric utilities), H57(procurement), C31(treatment effect models)

\footnotetext{
¥ Corresponding author. National Graduate Institute for Policy Studies. 7-22-1 Roppongi, Minato Tokyo 106-8677, Japan. Tel: +81-3-6439-6129, Fax: +81-3-6439-6010, E-mail: nhosoe@grips.ac.jp.

$\dagger$ Graduate School of Economics and Business Administration, Hokkaido University. Kita 9 Nishi 7, Kita, Sapporo 060-0809, Japan. Tel: +81-11-706-3864, Fax: +81-11-706-4947, E-mail: stakagi@econ.hokudai.ac.jp.
} 


\section{Introduction}

To design better electric power industry reforms, it is essential to measure the effects of regulatory reforms and examine their achievements. The impact of regulatory reforms on power charges is one of the clearest types of evidence for this purpose. We investigate how much the regulatory reform in the retail market of the power industry promoted competition between the incumbents and the entrants and consequently lowered power charges. We take a micro-data approach to this issue, using public power procurement auction data while paying attention to an endogeneity problem in the entrants' decisions about whether to submit bids for individual auctions.

In 1995, Japan initiated a series of regulatory reforms toward market-oriented power industry by deregulating entry in the wholesale power market. While establishing new rules and regulations for fair and efficient uses of the power network under the new regime, new power companies, called power producers and suppliers (PPSs), were allowed to engage in the retailing business of electric power competing with the incumbents that had long regionally monopolized the power market in Japan. The scope of this retail market deregulation was first set to large-scale industrial and commercial customers using 2,000 $\mathrm{kW}$ or more of ultra-high voltage (UHV) power, and then gradually enlarged to other middle-scale customers using $500 \mathrm{~kW}$ or more of high voltage power in 2004 , and further to those using $50 \mathrm{~kW}$ or more in 2005 . How significant was the impact of the reform on the retail power market?

Kainou (2007) examined power companies' financial statements and found that the regional power companies had drastically restructured their investment and recurrent expenses to cut power charges in the 1990 s by about $5 \%$, anticipating the soon-coming severe competition induced by the reforms. The Agency for Natural Resources and Energy (ANRE) (2004) conducted an analysis using auction data for power supply to government and other public entities, which explicitly report whether there was competition among power companies, or typically, between the incumbents and the PPSs. It divided the original 
sample into two subsamples consisting of (A) samples with a single bidder and (B) samples with two or more bidders to compare the means of their power charges while controlling for effects of load factor. ${ }^{1,2}$ It found that, in the cases with load factors no higher than $50 \%$, the mean of the power charges in Group A was higher than that in Group B. That is, the competition led to a charge decline. This impact depends on load factor, which correlates with the likelihood of the PPSs' entry and thus the keenness of competition. For users with a load factor of, say, $30 \%$, competition lowered the power charge by about $4 \% .^{3}$

Nevertheless, ANRE (2004) did not take into account the decision-making process by which the PPSs decide whether to bid in individual auctions. The data imply that while the incumbents bid in almost all auctions, the PPSs seem to carefully select only profitable ones that they had a sufficiently high probability of winning so as not to bear bidding costs for auctions they were likely to lose. In fact, as ANRE (2004) pointed out, the PPSs focus on cases with a load factor of about $30-50 \%$. This suggests that the scope of competition is endogenously determined by the PPSs' bid-submission decision while the scope of deregulation is exogenously defined by the laws and ordinances. ${ }^{4}$ Therefore, if we simply

1 The average power charge is computed by dividing the winning bids (yen) by the (planned) power demand (kWh). We also use it as the power charge to examine in our study and simply call it the power charge unless otherwise indicated.

2 (Annual average) load factor is defined as follows:

Load factor $(\%)=($ planned $)$ power demand $(\mathrm{kWh})$

$/[$ contract demand $(\mathrm{kW}) * 365($ days $) * 24($ hours $) *$ contract period $($ year $)] * 100(\%)$.

Given the total power demand, lower load factor implies that capacity is more likely to be idle and thus that such customers are costly to serve.

3 This is the authors' estimate using the model developed by ANRE (2004).

${ }^{4}$ More precisely, in the public procurement cases, public entities can exceptionally accept power supply from the PPSs for the sake of transparency in public procurements even if the case is out of the scope of the retail market deregulation. However, such exceptional cases tend to be small-scale contracts and thus rarely put out to bid due to the transaction costs borne by public entities. 
divide the original sample into these two subsamples using ex post information about the states of competition, we cannot estimate the true impact of the retail market deregulation through competition.

Hattori (2010) analyzed the bid submission by explaining the number of PPS bidders with attributes of individual auctions. Hattori (2010) found that the number of PPS bidders was increased by such factors as lower load factor, larger contract demand, and ultra-high voltage power supply, using a sample encompassing 949 public auctions for power supply starting in fiscal 2004-2006. He, however, did not investigate the impact of the number of PPS bidders or the state of competition on power charges. Hattori and Saegusa (2010) extended Hattori's (2010) study with the auction data for 2008 to measure the impact of the regulation of bidders' eligibility in regard to their carbon dioxide emissions on the number of bidders, PPSs' winning probability, winners' carbon dioxide emissions, and winning bids. They found that such environmental considerations raised the winning bids by $1.6 \%$ through discouraging PPSs from submitting bids.

In this study, we use a dataset recording the results of about 500 public auctions in five regional markets in Japan, which observed some PPSs' bids for the power supply scheduled to start in 2005 to investigate (A) what factors affected the PPSs' bid-submission decision and (B) what factors determined the bids correcting the sample-selection bias caused by (A). By comparing the actual winning bids in the multiple bidder cases with the counter-factual bids predicted by supposing that only one bidder would have hypothetically submitted a bid in the same cases, we quantify the impact of the retail market deregulation on power charges through competition. Our results suggest that the competition significantly lowered the power charges by $0.48 \mathrm{yen} / \mathrm{kWh}$ on average.

Our paper proceeds as follows. In Section 2, we provide basic statistics of our public auction sample and suggest some econometric issues concerning the endogeneity of the PPSs' bid-submission. Section 3 shows our strategies for estimating power charges correcting the sample-selection bias due to this endogeneity and for measuring the impact of the retail 
market deregulation on power charges through competition. Section 4 shows our estimation results, followed by the concluding Section 5 .

\section{Auction Data of Electric Power Procurement and Econometric Issues}

\subsection{Electric Power Procurement Auction}

Japan's power market consumed 918 billion $\mathrm{kWh}$ in 2005, of which 560 billion $\mathrm{kWh}$, or $61 \%$ of the total demand, was within the scope of the retail market deregulation. The PPSs covered only 11 billion $\mathrm{kWh}$ (1.2\% of the total demand, $2.0 \%$ of the deregulated market demand). Our sample comprises public auctions for power supply to the government and other public entities which disclose details of the results about whether or not a single company bid in the five regions (Tokyo, Chubu, Kansai, Chugoku, and Kyushu) where the PPSs had ever bid. After conducting sample selection as discussed in Section 4, our sample encompasses 489 auctions, which planned to consume 4.9 billion $\mathrm{kWh}(0.9 \%$ of the total demand in the deregulated retail market) worth 57.3 billion yen.

The observed power charges (i.e., the winning bids) show a downward-sloping curve, reflecting the usual two-tier charge system based on capacity and demand charges (Figure 1). The descriptive statistics of our sample (after the sample selection) are shown by region in Table 1 and by load factor in Table 2 . 
Figure 1: Average Power Charges and the Load Factor

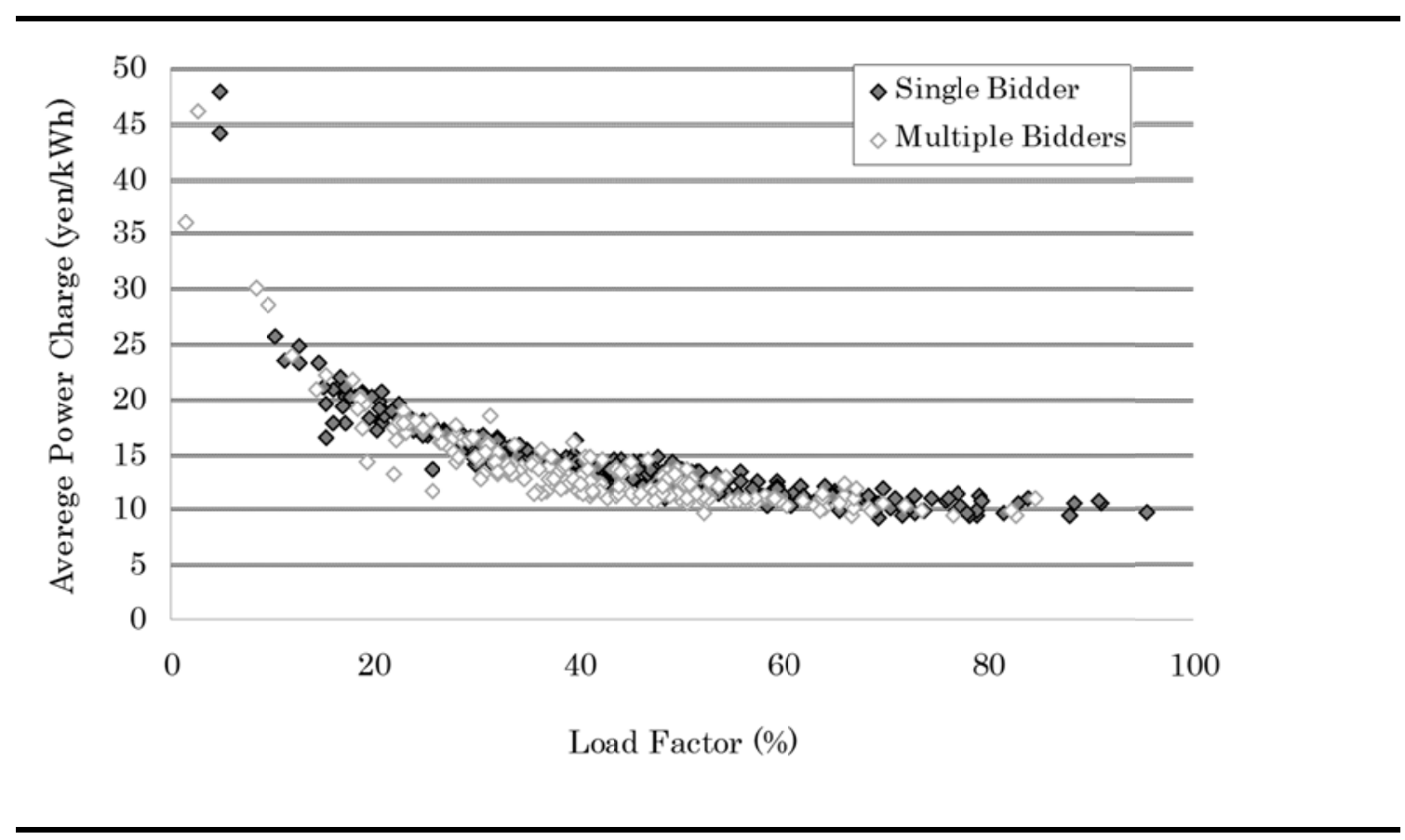


Table 1: Descriptive Statistics

\begin{tabular}{|c|c|c|c|c|c|c|c|}
\hline Region & $\begin{array}{c}\text { Mean } \\
\text { Power } \\
\text { Charges } \\
\text { (yen/kWh) }\end{array}$ & $\begin{array}{c}\text { Share } \\
\text { of } \\
\text { UHV } \\
(\%)\end{array}$ & $\begin{array}{l}\text { Mean } \\
\text { Load } \\
\text { Factor } \\
\quad(\%)\end{array}$ & $\begin{array}{c}\text { Mean } \\
\text { Contract } \\
\text { Demand } \\
(\mathrm{kW})\end{array}$ & $\begin{array}{c}\text { Total [Mean] } \\
\text { Bid } \\
\text { (bil. yen) }\end{array}$ & $\begin{array}{c}\text { Total [Mean] } \\
\text { Power Demand } \\
\quad(\text { bil. kWh) }\end{array}$ & $\begin{array}{c}\text { No. } \\
\text { of } \\
\text { Obs. }\end{array}$ \\
\hline \multicolumn{8}{|l|}{ Tokyo } \\
\hline Single Bidder & 12.88 & 22.45 & 52.81 & 2177.29 & $12.35[0.126]$ & $1.07[0.011]$ & 98 \\
\hline Multiple Bidders & 13.14 & 57.84 & 42.95 & 3001.07 & $17.74 \quad[0.174]$ & $1.53[0.015]$ & 102 \\
\hline Regional Total & 13.07 & 40.50 & 47.78 & 2598.14 & $30.09 \quad[0.151]$ & $2.60 \quad[0.013]$ & 200 \\
\hline \multicolumn{8}{|l|}{ Chubu } \\
\hline Single Bidder & 14.43 & 20.00 & 41.07 & 1305.12 & 7.58 [0.084] & $0.62[0.007]$ & 90 \\
\hline Multiple Bidders & 13.91 & 80.00 & 35.47 & 2267.50 & $1.87[0.094]$ & $0.15[0.007]$ & 20 \\
\hline Regional Total & 14.33 & 30.91 & 40.05 & 1480.10 & $9.45[0.086]$ & $0.77[0.007]$ & 110 \\
\hline \multicolumn{8}{|l|}{ Kansai } \\
\hline Single Bidder & 13.75 & 32.14 & 44.12 & 2057.00 & $3.11[0.111]$ & $0.27[0.010]$ & 28 \\
\hline Multiple Bidders & 13.10 & 83.72 & 45.27 & 3780.19 & $7.98 \quad[0.186]$ & $0.71[0.017]$ & 43 \\
\hline Regional Total & 13.36 & 63.38 & 44.82 & 3100.62 & $11.09[0.156]$ & $0.98 \quad[0.014]$ & 71 \\
\hline \multicolumn{8}{|l|}{ Chugoku } \\
\hline Single Bidder & 14.79 & 17.65 & 41.70 & 1211.96 & $3.28[0.064]$ & $0.27[0.005]$ & 51 \\
\hline Multiple Bidders & 14.37 & 55.56 & 36.48 & 2078.67 & $0.80 \quad[0.089]$ & $0.06[0.007]$ & 9 \\
\hline Regional Total & 14.72 & 23.33 & 40.92 & 1341.97 & $4.08[0.068]$ & $0.34[0.006]$ & 60 \\
\hline \multicolumn{8}{|l|}{ Kyushu } \\
\hline Single Bidder & 15.55 & 5.56 & 34.60 & 776.14 & $1.28[0.036]$ & $0.09[0.003]$ & 36 \\
\hline Multiple Bidders & 13.78 & 50.00 & 39.94 & 2344.67 & $1.35[0.112]$ & $0.11[0.009]$ & 12 \\
\hline Regional Total & 15.11 & 16.67 & 35.93 & 1168.27 & $2.63[0.055]$ & $0.20[0.004]$ & 48 \\
\hline \multicolumn{8}{|l|}{ Total } \\
\hline Single Bidder & 14.06 & 19.80 & 44.48 & 1578.16 & $27.61[0.091]$ & $2.33[0.008]$ & 303 \\
\hline Multiple Bidders & 13.31 & 65.59 & 42.17 & 3015.33 & $29.74 \quad[0.160]$ & $2.56[0.014]$ & 186 \\
\hline Total & 13.78 & 37.22 & 43.60 & 2124.81 & $57.34 \quad[0.117]$ & $4.89[0.010]$ & 489 \\
\hline
\end{tabular}

Note: UHV stands for ultra-high voltage.

Table 2: Power Charges by Load Factor and the State of Competition

\begin{tabular}{|c|c|c|c|c|c|c|c|c|}
\hline \multirow[b]{2}{*}{$\begin{array}{l}\text { Load } \\
\text { Factor }\end{array}$} & \multicolumn{2}{|c|}{$\frac{\text { Single Bidder }}{\text { Sample }}$} & \multicolumn{2}{|c|}{$\frac{\text { Multiple Bidder }}{\underline{\text { Sample }}}$} & \multirow{2}{*}{$\begin{array}{c}\text { Difference } \\
\text { of Mean } \\
\text { Power } \\
\text { Charges } \\
\text { (yen/kWh) }\end{array}$} & \multirow[b]{2}{*}{$\begin{array}{c}\text { Share of } \\
\text { Multiple } \\
\text { Bidder } \\
\text { Sample } \\
(\%)\end{array}$} & \multicolumn{2}{|c|}{$\frac{\text { Whole }}{\text { Sample }}$} \\
\hline & $\begin{array}{c}\text { Mean } \\
\text { Power } \\
\text { Charges } \\
\text { (yen/kWh) }\end{array}$ & $\begin{array}{l}\text { No. } \\
\text { of } \\
\text { Obs. }\end{array}$ & $\begin{array}{c}\text { Mean } \\
\text { Power } \\
\text { Charges } \\
\text { (yen/kWh) }\end{array}$ & $\begin{array}{l}\text { No. } \\
\text { of } \\
\text { Obs. }\end{array}$ & & & $\begin{array}{c}\text { Mean } \\
\text { Power } \\
\text { Charges } \\
\text { (yen/kWh) }\end{array}$ & $\begin{array}{l}\text { No. } \\
\text { of } \\
\text { Obs. }\end{array}$ \\
\hline$\overline{10-20 \%}$ & 20.89 & 21 & 19.92 & 10 & -0.97 & 32.26 & 20.57 & 31 \\
\hline $20-40 \%$ & 15.98 & 112 & 14.61 & 77 & -1.37 & 40.74 & 15.42 & 189 \\
\hline $40-60 \%$ & 12.77 & 105 & 12.04 & 74 & -0.73 & 41.34 & 12.47 & 179 \\
\hline $60-80 \%$ & 10.66 & 56 & 10.50 & 22 & -0.16 & 28.21 & 10.62 & 78 \\
\hline $80-100 \%$ & 10.30 & 9 & 10.09 & 3 & -0.21 & 25.00 & 10.25 & 12 \\
\hline Total & 14.06 & 303 & 13.31 & 186 & -0.69 & 38.04 & 13.78 & 489 \\
\hline
\end{tabular}

Table 2 suggests the popularity of competition between the incumbents and the 
PPSs-multiple bidders appear in 186 cases ( $38 \%$ of the whole sample) in the five regions. At a glance, the data suggest that the multiple bidder cases were likely to result in about 0.7 yen/kWh lower charges on average than the single bidder cases. This is found more or less commonly in all load factor classes but is especially conspicuous in the load factor classes lower than $60 \%$. Examining the winners of multiple-bidder auctions, we find the PPSs aggressively bid to almost completely beat the incumbents. ${ }^{5}$ This led to these significant bid charge gaps in these market segments.

It is notable that the PPSs' bids were more highly concentrated upon the load factor range from 20 to $60 \%$. About $80 \%$ of the multiple bidder cases were concentrated upon this range, although about $70 \%$ of the single bidder cases were there. This is probably because the customers with very high load factors had load profiles (i.e., a pattern of power demand within a day or a year) that matched well with the cheap power supplied by base-load plants (discussed below) and thus had already enjoyed the incumbents' generous offers even before the deregulation. The incumbents were equipped with many base-load plants using cheap fuels like nuclear; nuclear power plants generate about one-third of Japan's total power. In contrast, the PPSs were mainly equipped with small-scale oil-fueled thermal power plants for middle- or peak-load. The fuel costs for these are generally higher than the incumbents', particularly during off-peak load times like night. Bids of the PPSs with plant portfolios focused on middle- or peak-load supply could hardly undercut those of the incumbents for such high load factor customers consuming power all day and night. Conversely, the PPSs could provide competitive offers to low load factor customers who had faced relatively high charges offered by the incumbents before the reform.

Table 1 again suggests that the PPSs were more likely to bid for the ultra-high

\footnotetext{
${ }^{5}$ In 2005, no competition between the incumbents was observed at all in the public auctions. Moreover, due to our sample selection, the single bidder sample implies no companies but an incumbent bid; the multiple bidder sample does an incumbent and one or more PPSs bid. Therefore, the single bidder sample indicates the incumbents' bid patterns; the multiple bidder one does the PPSs'.
} 
voltage $(20,000 \mathrm{~V}$ or higher) power procurement cases. The share of the ultra-high-voltage cases in the multiple bidder cases is more than three times larger than that in the single bidder cases. This is because the wheeling charge, which was paid for uses of the incumbents' network to transmit power to customers, was set lower for the ultra-high voltage power than for high voltage power. Thus, the PPSs were more likely to bid on the ultra-high voltage cases.

Contract demand $(\mathrm{kW})$ is often highly correlated with the supply voltage for purely technological reasons. The contract demand of the multiple bidder sample is about twice as large as that of the single bidder sample. As bidding costs would depend little on the contract demand, power companies could more easily impute bidding costs to bid charges in larger-scale power supply cases and thus were more likely to bid in this market segment.

In this study, we aim to measure the magnitude of power charge declines attributable to competition that was induced by the retail market deregulation. As discussed above, this decline did not appear uniformly across the scope of the deregulation. That is, while auctions with the PPSs' bids were likely to experience a charge decline, those without any PPSs' bids led to only a smaller charge decline or a rise induced by the monopolistic behavior of power companies. To analyze this problem, we examine the bid-submission behavior of power companies and its endogeneity.

\subsection{Econometric Issues in the PPSs' Endogenous Bid-submission Decision}

Given the observations summarized above, we have to consider two situations regarding the state of competition in individual auctions. One is that there is no bidder other than an incumbent (the single bidder case); the other is that there is an incumbent and one or more PPSs competing with each other (the multiple bidder case). How much charge difference would arise between these two situations? By comparing the power charges observed in the actual multiple-bidder cases with counter-factual power charges which 
would have been observed in the hypothetical single-bidder cases, we measure the effects of competition on power charges (Figure 2). In the following, we call this the "multiple-bidder effect."

In Figure 2, we illustrate the schedules of their offers as downward-sloping curves that intersect with each other at some point. As discussed in Section 2.1, the incumbents usually had a comparative advantage in high load factor cases; the PPSs did in low load factor cases. Thus, the PPSs' offer curve is steeper than the incumbents'. On one hand, the public notices about the results of auctions report no bids but the winning ones, which constitute the lower envelope of these two schedules. On the other hand, losing bids, including unobservable offers which power companies gave up making, are not publicly available. That is, there is no way at all to observe both the winning and losing bids made for individual auctions. Therefore, we need to develop a method to predict unobservable power charges under two different states of competition. 
Figure 2: Observed Bids and Unobserved Offers

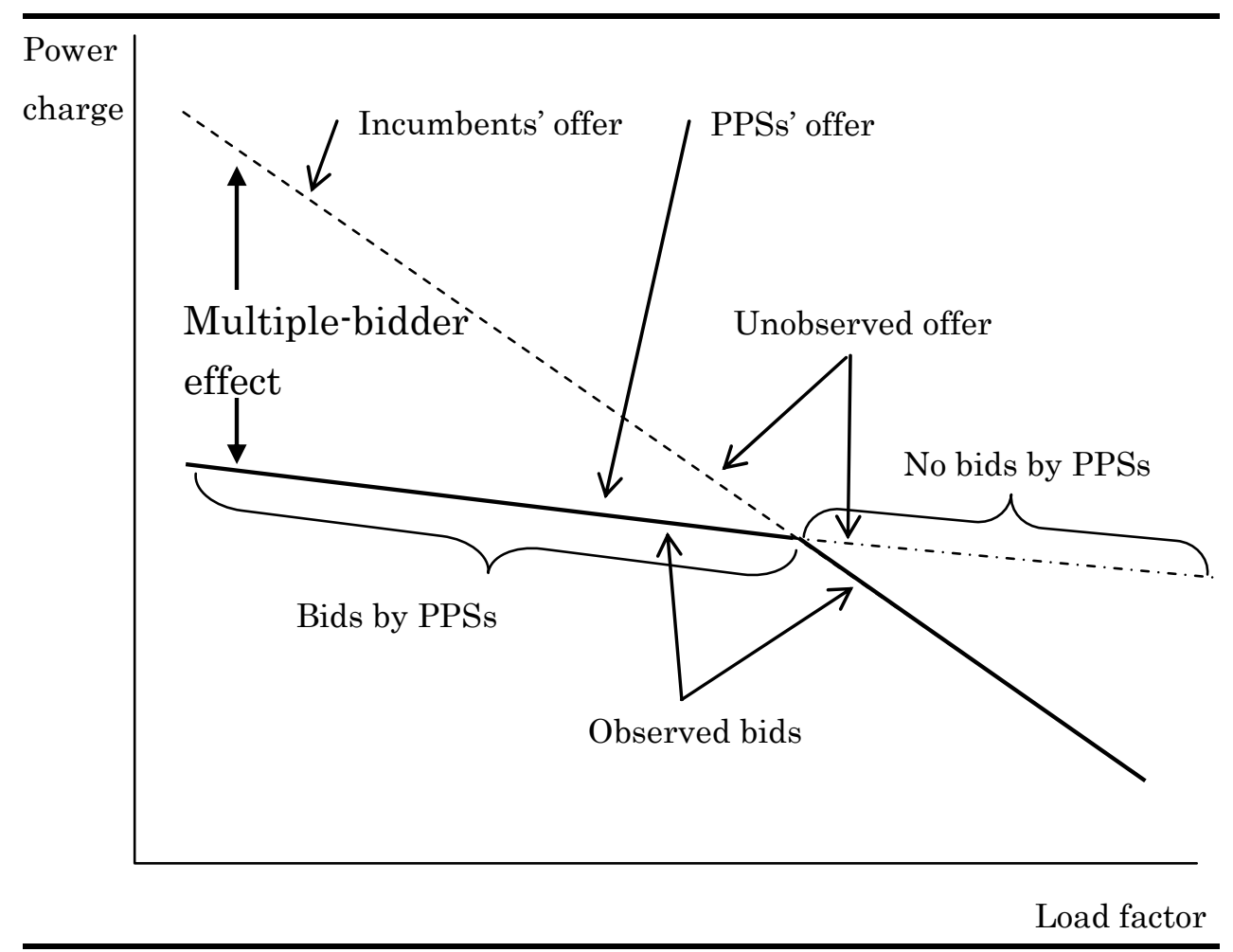

Note: In general, the placements of these two offer schedules do not necessarily appear as Figure 2 illustrates. However, we draw this figure to illustrate the gist of our estimation result shown later.

Presuming the incumbents submit bids in all auctions, if the PPSs' bid-submission is determined in a perfectly random manner irrespective of the attributes of auctions, we can measure the effect of competition on charges by comparing the means of the two groups' power charges with and without PPSs' bid as Wooldridge (2001) showed. However, Figure 1 indicates some correlation between the likelihood of the PPSs' bid-submission and the load factor. That is, the PPSs' bid-submission decision is endogenously made more or less considering the attributes of auctions like load factor. If this is the case, our estimates of power charges will suffer from the sample selection bias.

Suppose the bid-submission decision is determined only by auctions' observable attributes, such as load factor and users' facility types, but independent of unobservable 
factors affecting power charges, we can apply the propensity score method to generate weights to correct the sample selection bias due to the PPSs' endogenous bid-submission decision. ${ }^{6}$ However, this approach will be found in vain when we have some unobservable factors which affect the PPSs' bid-submission decision and (winning) bid charges, such as profiles of PPSs' customers and their remaining supply capacity available at the point of their bid-submission decision. To remedy this, we can employ a proxy variable so as to take account of such private information like the supply capacity as discussed in Section 3. Nonetheless, if this proxy variable does not work enough to control for effects of such unobservable factors, the supply capacity still turns out one of unobservable factors causing such a bias. In sum, if the PPSs' private information, exemplified by their supply capacity, affects the bid-submission decision and the power charges, we cannot make the bid-submission decision independent of the observed winning bid charges using any observable factors as explanatory variables. Consequently, any methods with the propensity scores, and still less the above-mentioned simple method of choosing the treatment and control group samples, cannot fully correct the sample-selection bias.

From the point of view of game-theory analysis, the auctions in our dataset are first-price sealed-bid auctions. There are two types of bidders: regional power companies and PPSs. Obviously, they are asymmetric players in company size and cost structure as well as their entry behavior, as mentioned above. Auction studies, such as Paarsh and Hong (2006) and $\mathrm{Li}$ and Zheng (2009), often call for a structural approach in the independent private-value paradigm. However, their empirical approaches, which use a simplifying assumption of symmetry among bidders, cannot be immediately taken in our case with such asymmetry. Although we may be able to extend their framework to the asymmetric case, lack of information about losing bidders and their bids leads to an insufficient sample size for this purpose. Therefore, we take a reduced-form approach here rather than a structural

\footnotetext{
${ }^{6}$ About the propensity score method, see, for example, Dehejia and Wahba (2002).
} 
one.

In the following, we elaborate our model to precisely measure the multiple-bidder effect. To this end, we describe the PPSs' endogenous bid-submission decision and the winning bid charges with an explicit consideration about their interdependence through unobservable factors.

\section{Estimating Power Charges Considering Endogenous}

\section{Bid-submission}

\subsection{Modeling PPSs' Endogenous Bid-submission}

Let us indicate the competition state by the suffix $j$ : the single bidder state $(j=0)$ and the multiple bidder state $(j=1)$. Let $y_{j, i}$ and $y_{i}$ denote the bid for the $i^{-t h}$ auction in the $\mathrm{j}$-th state of competition and the actual observation of power charges (i.e., the winning bid charges) in the i-th auction. The state of competition is determined by the PPSs' bid-submission decision because the incumbents always submit bids. In sum, $y_{0, i}$ indicates the power charge observed in the $\mathrm{i}$-th auction with a single bidder. PPSs are supposed to decide whether to bid or not in individual auctions considering attributes of auctions and PPSs' own private factors. $y_{1, i}$ indicates the power charge observed in the $\mathrm{i}$-th auction with multiple bidders (one incumbent and one or more PPSs). A dummy variable $d_{i}$ indicates PPSs' bid-submission decision whether to bid $(=1)$ or not $(=0)$ in the $\mathrm{i}$-th auction.

Every time PPSs submit a bid, they bear various bidding costs in each bid, such as costs for preparing bids, companies' general and administrative expenses, and the opportunity costs of supply capacity consumed in the bid. Therefore, the PPSs will bid only when they anticipate high probability to win and earn enough profits. In other words, anticipating the incumbents' bid choice $y_{0, i}^{*}$, the PPSs make their bid choice $y_{1, i}^{*}$ given the 
bidding costs (expressed in terms of yen per $\mathrm{kWh}) c_{i}^{*}$ as follows.

$$
d_{i}=\left\{\begin{array}{ccc}
1 & \text { if } & y_{0, i}^{*} \geq y_{1, i}^{*}+c_{i}^{*} \\
0 & & \text { otherwise. }
\end{array}\right.
$$

By specifying $y_{j, i}^{*}$ and $c_{i}^{*}$ as

$$
\begin{aligned}
& y_{j, i}^{*}=\mathbf{k}_{j, i} \xi_{j}+u_{j, i}, \quad j=0,1, \\
& c_{i}^{*}=\mathbf{w}_{i} \pi+v_{i},
\end{aligned}
$$

we can boil down this system into the following binary choice model. ${ }^{7}$

$$
d_{i}=1\left\{\mathbf{z}_{i} \gamma+\varepsilon_{i} \geq 0\right\}
$$

Note that $1\{\bullet\}$ in Eq. (1) is an indicator function which returns unity if the condition within the brackets holds, and zero otherwise. The vector $\mathbf{z}_{i}$ consists of observable factors included in the formulas characterizing $y_{j, i}^{*}$ and $c_{i}^{*} ; \varepsilon_{i}$ encompasses unobservable factors $u_{j, i}$ and $v_{i}$ like PPSs' private information about available capacity, customer profiles, plant development plans, and so on, used in their bid-submission decision and bid choice.

In our estimation, we use load factor (\%) as one of the explanatory variables in $\mathbf{z}_{i}$, following ANRE (2004) and Hattori (2010). As indicated in Table 4, we also include the supply voltage dummy (ultra-high voltage $=1$, high voltage $=0$ ), the contract demand size $(\mathrm{kW})$, and regional dummies for the Tokyo area, the Chubu area, the Kansai area and other areas as the explanatory variables.

\footnotetext{
${ }^{7}$ In this study, we develop a model that presumes one representative PPS in the market; however, in reality there are several PPSs behaving individually. If we explicitly model the number of PPSs participating in competition following Hattori (2010), we can consider the effect of variable degrees of competition among power companies. However, as there were many auctions which did not disclose the number of bidders, our sample size becomes considerably small in this approach. Therefore, we omit the details of the model in this regard.
} 
Table 3 Average Load Factor by Facility Type

\begin{tabular}{|c|c|c|c|c|c|c|c|c|c|}
\hline \multirow[b]{2}{*}{ Type of Facility } & \multicolumn{3}{|c|}{ Single Bidder Sample } & \multicolumn{3}{|c|}{ Multiple Bidder Sample } & \multicolumn{3}{|c|}{ Whole Sample } \\
\hline & $\begin{array}{l}\text { Mean } \\
\text { Load } \\
\text { Factor } \\
(\%)\end{array}$ & S.D. & $\begin{array}{l}\text { No. } \\
\text { of } \\
\text { Obs. }\end{array}$ & $\begin{array}{c}\text { Mean } \\
\text { Load } \\
\text { Factor } \\
(\%) \\
\end{array}$ & S.D. & $\begin{array}{c}\text { No. } \\
\text { of } \\
\text { Obs. }\end{array}$ & $\begin{array}{l}\text { Mean } \\
\text { Load } \\
\text { Factor } \\
(\%)\end{array}$ & S.D. & $\begin{array}{l}\text { No. } \\
\text { of } \\
\text { Obs. }\end{array}$ \\
\hline Water \& Sewage & 59.52 & 18.01 & 97 & 51.60 & 16.18 & 10 & 58.78 & 17.99 & 107 \\
\hline Road & 48.27 & 9.50 & 3 & 41.77 & 17.24 & 11 & 43.16 & 16.13 & 14 \\
\hline Garbage & 40.50 & 20.30 & 11 & 69.56 & 0.00 & 1 & 42.92 & 21.03 & 12 \\
\hline School & 40.75 & 12.37 & 11 & 41.80 & 11.20 & 15 & 41.36 & 11.72 & 26 \\
\hline Hospital & 46.59 & 9.31 & 35 & 49.32 & 8.20 & 30 & 47.85 & 8.92 & 65 \\
\hline Market & 34.19 & 5.81 & 4 & 45.69 & 0.80 & 3 & 39.12 & 7.21 & 7 \\
\hline Office Building \& Others & 34.50 & 13.19 & 142 & 39.27 & 15.01 & 116 & 36.64 & 14.23 & 258 \\
\hline Total & 44.48 & 18.42 & 303 & 42.17 & 14.69 & 186 & 43.60 & 17.13 & 489 \\
\hline
\end{tabular}

As the facility type implies miscellaneous information like a load profile, we set up seven facility type categories as shown in Table 3. Given these categories, our dataset includes only one multiple-bidder observation in the garbage facility group; we merge the garbage facility group into the office building and others group to avoid problems due to multicollinearity in our estimation. Thus, we use five facility dummies in our model while choosing the "office building and others" as the reference type. Lastly, we prepare a proxy variable of the PPSs' supply capacity, which is computed as a ratio of the contract demand $(\mathrm{kW})$ of individual auctions to the total supply capacity held by the nine largest PPSs 12 months prior to the beginning of the contract period. ${ }^{8}$

\subsection{Modeling Determinants of Power Charges}

Given the bid-submission decision $d_{i}$ discussed above, our power charge function for the $\mathrm{i}^{\text {-th }}$ auction is formulated as:

$$
y_{j, i}=\mathbf{x}_{i} \beta_{j}+\eta_{j, i} \quad j=0,1,
$$

\footnotetext{
8 Data source: "Denryoku chosa tokei geppo (Monthly power demand survey)" by the ANRE.
} 


$$
y_{i}=d_{i} \cdot y_{1, i}+\left(1-d_{i}\right) \cdot y_{0, i}
$$

In this model, we take account both of observable factors $\mathbf{x}_{i}$ and unobservable ones $\eta_{j, i}$. The former encompasses load factor (\%), the ultra-high voltage dummy, the regional dummies, the facility type dummies, the contract period (year), and the logarithm of contract demand $(\mathrm{kW})$. Regarding the load factor, Figure 1 suggests that the power charge sharply falls when the load factor is low and gradually converges to about 10 yen/kWh as the load factor approaches $40 \%$ or higher. In estimating the effects of the load factor on the power charges, we take two alternative approaches to cope with such nonlinearities in the load factor curves; one is the parametric approach incorporating linear, quadratic, and inverse terms of load factor, and the other is the nonparametric approach approximating the power charge curves by some flexible curves.

To estimate the unknown parameters in Eqs. (1) and (2), we have to introduce several assumptions about the model. First, we assume that the unobservable factors $\varepsilon_{i}$ and $\eta_{j, i}$ follow an independent multivariate t-distribution (Kotz and Nadarajah (2004)) with $v$ degrees of freedom. Equivalently, we assume the scale mixture density of $\left(\eta_{j, i}, \varepsilon_{i}\right)^{\prime}$ and $\lambda_{i}$, where

$$
\left(\begin{array}{c}
\eta_{j, i} \\
\varepsilon_{i}
\end{array}\right) \mid \lambda_{i} \sim N\left(0, \lambda_{i}^{-1} \mathbf{\Omega}_{j}\right), \quad \mathbf{\Omega}_{j}=\left(\begin{array}{cc}
\sigma_{j}^{2} & \rho_{j} \sigma_{j} \\
\rho_{j} \sigma_{j} & 1
\end{array}\right), \quad i=1,2, \ldots, n,
$$

and $\lambda_{i} \sim \operatorname{gamma}(v / 2, v / 2)$. The system consisting of Eqs. (1)-(4) is called an endogenous regime-switching regression model. ${ }^{9}$

The model consisting of Eqs. (1)-(3) with the parametric load factor curves, or with the nonparametric ones, is estimated by a Markov Chain Monte Carlo (MCMC) method. Following the estimation methods by Chib (2007) and Chib and Jeliazkov (2006), we

\footnotetext{
9 See, for example, Heckman (1976) and Maddala (1983).
} 
describe the details of our slightly modified algorithm in the Appendix. In Section 4, we present our estimation results.

\subsection{Definition of the Multiple Bidder Effect and its Estimation}

Given Eqs. (1)-(3), we measure the multiple bidder effect, which captures the gaps between the power charges in the multiple bidder state and those in the single bidder state. We define the multiple bidder effect as follows:

$$
T=E\left[y_{1, i}-y_{0, i} \mid d_{i}=1\right]
$$

This multiple bidder effect $T$ compares, given the PPSs' bid $\left(d_{i}=1\right)$, the mean of actual power charges observed in the multiple bidder state $E\left[y_{1, i} \mid d_{i}=1\right]$ with that of counter-factual power charges computed for the same auctions in the hypothetical single bidder state $E\left[y_{0, i} \mid d_{i}=1\right]$. Graphically speaking, this effect corresponds to the gap between the two offer schedules only for market segments with lower load factors than that indicated by the intersection of these two schedules in Figure 2. If the competition induced by the deregulation successfully promotes competition to lower charges, the measurement $T$ turns out negative.

In addition, we can define more detailed measurement. As discussed in Section 2.1, the keenness of competition between the incumbents and the PPSs differs depending on the auctions' attributes, particularly load factor and the supply voltage type. We measure the multiple bidder effect in each market segment characterized by these two attributes. Let $l$ and $\mathfrak{I}_{k}(k=1,2, \ldots, K)$ denote load factor (or the supply voltage type) and its intervals indicating the market segments. We define the measurement of the multiple bidder effect in the $\mathrm{k}$-th particular market segment as follows.

$$
T\left(\mathfrak{J}_{k}\right)=E\left[y_{1, i}-y_{0, i} \mid d_{i}=1, l \in \mathfrak{J}_{k}\right] .
$$

In the following, we use the public procurement auction data to estimate the 
system consisting of Eqs. (1)-(4) and measure (5) and (5') with the estimated model. As Heckman et al. (2003) showed, the estimators $T_{n}(\boldsymbol{\theta})$ and $T_{n}\left(\boldsymbol{\theta}, \mathfrak{J}_{k}\right)$ are the sample analogues to $T$ and $T\left(\mathfrak{J}_{k}\right)$ for a given parameter $\boldsymbol{\theta}$, respectively:

$$
\begin{aligned}
& T_{n}(\boldsymbol{\theta})=\frac{1}{\sum_{i=1}^{n} d_{i}} \sum_{i=1}^{n} d_{i} \cdot\left\{\mathbf{x}_{i}\left(\boldsymbol{\beta}_{1}-\boldsymbol{\beta}_{0}\right)+\left(\rho_{1} \sigma_{1}-\rho_{0} \sigma_{0}\right) \frac{v+\left(\mathbf{z}_{i} \gamma\right)^{2}}{v-1} \frac{t_{v}\left(\mathbf{z}_{i} \gamma\right)}{T_{v}\left(\mathbf{z}_{i} \gamma\right)}\right\}, \\
& T_{n}\left(\boldsymbol{\theta}, \mathfrak{J}_{k}\right)=\sum_{i=1}^{n} \frac{d_{i} f_{i, k}}{\sum_{j=1}^{n} d_{j} f_{j, k}} \cdot\left\{\mathbf{x}_{i}\left(\boldsymbol{\beta}_{1}-\boldsymbol{\beta}_{0}\right)+\left(\rho_{1} \sigma_{1}-\rho_{0} \sigma_{0}\right) \frac{v+\left(\mathbf{z}_{i} \gamma\right)^{2}}{v-1} \frac{t_{v}\left(\mathbf{z}_{i} \gamma\right)}{T_{v+1}\left(\mathbf{z}_{i} \gamma\right)}\right\},
\end{aligned}
$$

where $f_{i, k}$ is a dummy variable being unity if the $\mathrm{i}$-th sample is within the $\mathrm{k}$-th market segment $\mathfrak{I}_{k}$, but zero otherwise. The estimates are obtained by integrating out the parameters from $T_{n}(\boldsymbol{\theta})$ and $T_{n}\left(\boldsymbol{\theta}, \mathfrak{J}_{k}\right)$ after being weighted with the posterior density. These are simply the averages of $T_{n}(\boldsymbol{\theta})$ and $T_{n}\left(\boldsymbol{\theta}, \mathfrak{I}_{k}\right)$ evaluating the parameter values from the MCMC outputs. Moreover, we apply the same method to define the detailed measurements of the multiple-bidder effect for the market segments characterized by the supply voltage type.

\section{Estimation Results}

\subsection{Bid-submission Decision and the Power Charge Function}

Prior to our estimation, we conduct the following sample selections. First, we exclude nine observations with load factor lower than $10 \%$, which are few but show extremely high charges as Figure 1 suggests, to avoid their unreasonably large impact on 
our estimation results. ${ }^{10}$ Second, we also exclude eight observations where no incumbents' bids were observed. As we aim to estimate power charges by modeling the PPSs' behavior while presuming the incumbents' bid submission, such observations are not considered here. While we present our main estimation results obtained with parametric specifications (including the linear, quadratic, and inverse term of load factor) with t-distributed error terms discussed in the Appendix, we have also tried some alternative specifications regarding the load-factor-related variables, e.g., with and without a higher order term of load factor, load factor curve specified by a nonparametric function, or with and without the facility type dummies, which are expected to be highly correlated with load factor as Table 3 shows. Comparing their estimation results with each other in view of the log-marginal likelihood statistics (Chib and Jeliazkov (2005)) and the deviance information criterion (DIC, Spiegelhalter et al. (2002)), we choose the specification with a parametric polynomial of load factor and the t-distributed error term. ${ }^{11}$ While specifications omitting the facility type dummies lead to a considerably low log-marginal likelihood, we do not find any significant differences in our estimates of the multiple bidder effect shown in Section 4.2. Table 4 presents our estimation results by the MCMC estimation method with Ox version 5.10 (Doornik (2007)). ${ }^{12}$

The second tier of Table 4 shows our estimation results of the PPSs' bid-submission function (1). Although Hattori (2010) found lower load factor led to a higher likelihood of PPSs' bid-submission, our results do not imply so. This is because the facility type dummies

\footnotetext{
10 Those excluded samples are auctions for garbage incinerator plants (seven samples) and baseball stadiums (two samples). The former are equipped with garbage-fueled thermal power generators and consume auxiliary power purchased from power companies. The latter consume electricity only occasionally within a day and a year. They may well be regarded as abnormal samples.

11 See Section A.2 in the Appendix for this details.

${ }^{12}$ In this study, we use the level of average power charges as the dependent variable; no significant difference is found in our results even if we use their logarithms.
} 
are highly correlated with their load factor as discussed above and capture most of this effect on the PPSs' bid-submission decision. In fact, the estimated coefficient of the water and sewage facility dummy, which has the highest load factor among the seven facility type categories shown in Table 3, turns out significantly negative. This implies that the PPSs were less willing to bid for such facility cases than the others. 
Table 4 Estimation Results

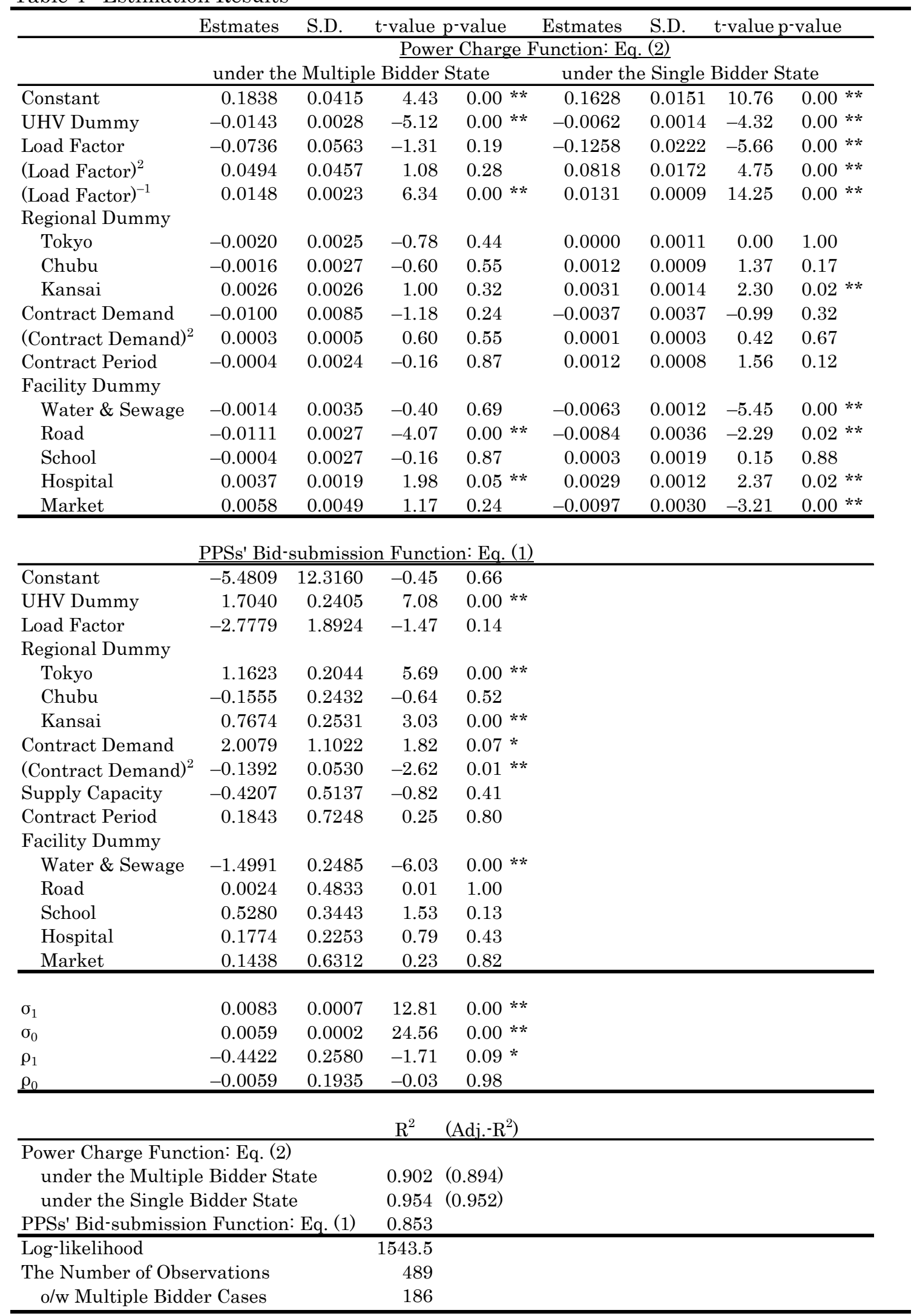

Note: $\quad * *$ and * indicate significant at $5 \%$ and $10 \%$ significance levels.

UHV stands for ultra-high voltage. 
The (logarithm of) contract demand $(\mathrm{kW})$ is found to give positive and significant impact on the PPSs' bid-submission decision. Regarding the supply voltage type, as Hattori (2010) found, the ultra-high voltage cases were likely to attract PPSs' bid. The regional dummies imply that the PPSs were more likely to bid in Tokyo and Kansai, where many PPSs' headquarters and branches are located. The measure of goodness of fit for our estimated function is about $85 \%$ in view of its prediction accuracy, which implies the PPSs' bid-submission model (1) can successfully estimate the PPSs' decision. ${ }^{13}$

The first tier of Table 4 shows our estimation results of the power charge function (2). The left panel, showing the power charge function with the PPSs' bid-submission, indicates that only the inverse term of load factor had significant impact on power charges. Given this functional form capturing the non-linear effect of load factor, its importance sharply diminishes as load factor increases and is visible as long as the load factor is no higher than $40 \%$.

The coefficients of the facility type dummies indicate that while hospitals and road facilities had a similar load factor, hospitals had higher bid charges; road facilities had lower charges (than office buildings and others). As the effect of the load factor is controlled for by its explanatory variables, we can interpret the coefficients of the facility type dummies as purely reflecting the differences of facilities' characteristics, such as load profiles. For example, road facilities consumed power mainly at night and enjoyed relatively lower

13 While using the standard $\mathrm{R}^{2}$ measure for Eq. (2), we use the odds ratio as a measure of goodness of fit for our binary choice model of Eq. (1). While the dependent variable takes zero or unity for individual auctions, we set its predicted values at unity when $\Phi\left(\mathbf{Z}_{i} \hat{\gamma}\right)$ exceeds 0.5 , but at zero otherwise. If the predicted values match their actual observations $d_{i}$, the prediction is accurate, and vice versa. The overall measure is computed by the share of accurate predictions in the whole sample. For more on the measures of goodness of fit, see Estrella (1998). 
charges, because their load profile better matched power supply by base-load power plants bearing cheap fuel costs. However, hospitals' load profile did not match the cheap power supply. Higher load factor and ultra-high voltage power supply led to significantly lower power charges as the earlier studies often pointed out. Compared with the results on the left panel, the right panel, showing the results of the power charge function without any PPSs' bid, indicates that the key factors affected the winning bid in a similar way and to a greater magnitude.

The third tier of Table 4 shows our estimation results of $\rho_{j}$ - the coefficients of correlation between the unobservable factors (i.e., $\varepsilon_{i}$ in the PPSs' bid-submission function (1) and $\eta_{j, i}$ in the power charge function (2)). The significance of the coefficient of correlation $\rho_{1}$ between $\varepsilon_{i}$ and $\eta_{1, i}$ implies, given the multiple bidder state that occurred, the PPSs' bid-submission decision was not independent of the power charge determination and that omitting their simultaneity generally led to biased estimates as discussed in Section 2.2. Thus, we cannot find the true impact of the retail market deregulation through competition by simply comparing observed charges between two subsample groups, distinguished only by observable factors such as the PPSs' bid-submission, load factor, and facility types. Moreover, the insignificance of the coefficient of correlation $\rho_{0}$ between $\varepsilon_{i}$ and $\eta_{0, i}$ implies the incumbents' bids did not have anything to do with the PPSs' bid-submission. In other words, the incumbents did not behave strategically in response to any actions by the PPSs.

\subsection{Measuring the Multiple-Bidder Effect}

Using our model shown above, we measure the multiple-bidder effect by (6) and (6'). Our estimates of the multiple-bidder effect $E\left[Y_{1, i}-Y_{0} \mid d_{i}=1\right]$, which is typically indicated by the gap between the two schedules only for the left side to their intersection in Figure 2, 
are computed by comparing the actual winning bid charges under the multiple bidder state $E\left[Y_{1, i} \mid d_{i}=1\right]$ with the counter-factual bid charges under the hypothetical single bidder state $E\left[Y_{0, i} \mid d_{i}=1\right]$. Table 5 indicates the power charge was cut by $0.48 \mathrm{yen} / \mathrm{kWh}$ due to competition on average. Examining the multiple-bidder effect by load factor class, the power charge declined by $0.45-0.54 \mathrm{yen} / \mathrm{kWh}$ in the load factor range from 20 to $60 \%$, on which the PPSs concentrated their bids. This is followed by the decline of $0.42 \mathrm{yen} / \mathrm{kWh}$ in the market segment with a load factor of $60-80 \%$. In the $80-100 \%$ load factor segment, although a significant decline is indicated, it cannot be a reliable estimate considering its sample size $(=12)$ and given our estimation strategy.

Table 5: Multiple-bidder Effects

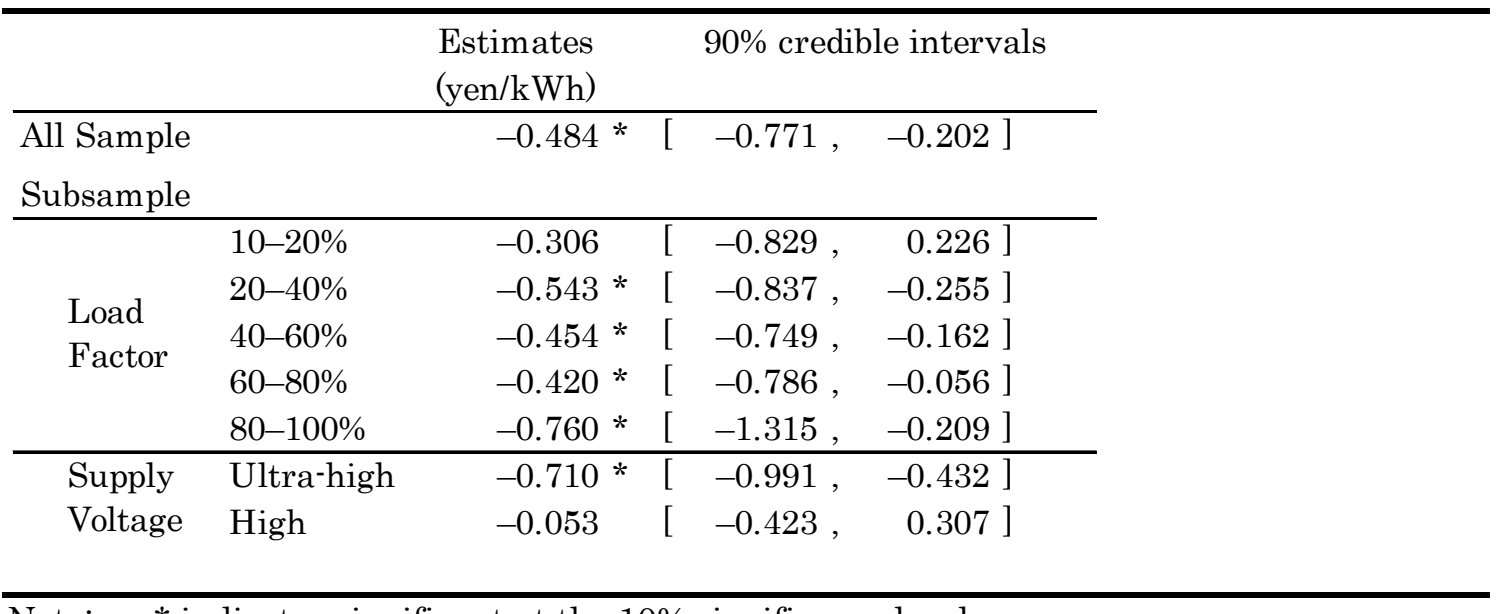

Note: $\quad$ * indicates significant at the $10 \%$ significance level.

While the descriptive statistics in Table 2 show that the charge differences by competition state were 1.37 and $0.73 \mathrm{yen} / \mathrm{kWh}$ in the market segments with the load factors of $20-40 \%$ and $40-60 \%$, the multiple-bidder effect reported in Table 5 (i.e., 0.54 and 0.45 yen $/ \mathrm{kWh}$ ) appears much smaller. This is not only due to the factors other than the load factor, but also due to the endogeneity of the PPSs' bid-submission decision as discussed in Section 2.2. That is, the true impact of competition induced by the retail market 
deregulation would be about half of the charge differences observed in such a casual comparison.

We do not find the multiple-bidder effect to be large; this is due to differences in resource endowments and available technologies between the incumbents and the PPSs. The PPSs' supply capacity was far from enough to serve all customers in the deregulated market: only $2 \%$ of the demand of the deregulated power market or about half of the power demand was examined in our auction data. Thus, it would be reasonable for us to infer that the PPSs could not compete on an equal footing with the incumbents in all market segments and instead each concentrated on its own niche, typically low load factor customers, and undercut the incumbents' bids slightly.

As for the market segments defined by supply voltage, we can discuss the PPSs' behavior in the same manner. In the ultra-high voltage cases, where relatively low wheeling charges are applied, the PPSs were more likely to bid to bring the multiple-bidder effect as high as $0.71 \mathrm{yen} / \mathrm{kWh}$; however, the high voltage users were found to be less profitable for the PPSs and faced relatively higher bid charges offered mainly by the incumbents. In other words, the scope of competition was limited to the ultra-high voltage segment.

\section{Concluding Remarks}

In this study, we have investigated the impact of the retail market deregulation on power charges through competition between the incumbents and the PPSs using public auction data. Contingent on the PPSs' bid-submission emulating the incumbents' bids, the power charges were cut by $0.48 \mathrm{yen} / \mathrm{kWh}$ on average. However, the scope of competition was limited mainly by the PPSs' supply capacity; there were many cases without any PPSs bids. Therefore, the impact of the retail market deregulation on the scope of competition and thus the charge declines achieved through competition will be heavily dependent on the present and future investment strategy of the PPSs.

In these ten years, commercial and industrial power charges have been decreased 
by 1.8 yen/kWh per annum in nominal terms. This decline can be attributed partly to the regulatory reforms, as Kainou (2007) discussed. By examining power procurement auction data, we measured the magnitude of the multiple-bidder effect. The data indicated that greater competition induced by the retail market reform contributed to the evolution of power charges.

Our sample only consists of power supply auctions starting in 2005. For the sake of transparency of public procurement, the number of auctions has been increasing year by year. In future work, we should append data for more recent years to our original sample to analyze how the bid-submission decision and the multiple-bidder effect have evolved in these years. 


\section{References}

Agency for Natural Resources and Energy (ANRE) (2004) "Denryoku-kyokyu-kosuto-tou-ni-kansuru Chosa (A Survey on Power Supply Costs)," March, Government of Japan, Tokyo (in Japanese).

Chib, S. (2007) "Analysis of Treatment Response Data without the Joint Distribution of Potential Outcomes," Journal of Econometrics 140, 410-412.

Chib, S., E. Greenberg, and I. Jeliazkov (2009) "Estimation of Semiparametric Models in the Presence of Endogeneity and Sample Selection," Journal of Computational and Graphical Statistics 18, 321-348.

Chib, S., and I. Jeliazkov (2005) “Accept-reject Metropolis-Hastings Sampling and Marginal Likelihood Estimation," Statistica Neerlandcia 59, 30-44.

Chib, S., and I. Jeliazkov (2006) "Inference in Semiparametric Dynamic Models for Binary Longitudinal Data," Journal of the American Statistical Association 101, 685-700.

Dehejia, R. H., and S. Wahba (2002) "Propensity Score-matching Methods for Nonexperimental Causal Studies," Review of Economics and Statistics 84 (1), 151161.

Doornik, J. A. (2007) Object-Oriented Matrix Programming Using Ox, 3rd ed. London: Timberlake Consultants Press and Oxford University Press: www.doornik.com.

Estrella, A. (1998) "A New Measure of Fit for Equations with Dichotomous Dependent Variables," Journal of Business and Economic Statistics 16 (2), 198-205.

Hattori, T. (2010) "Determinants of the Number of Bidders in the Competitive Procurement of Electricity Supply Contracts in the Japanese Public Sector," Energy Economics $32(6), 1299-1305$.

Hattori, T., and M. Saegusa (2010) "Denryoku-nyusatsu-ni-okeru Kankyo-hairyo-keiyaku-ni-kansuru Jissho-bunseki-susogiri-hoshiki-no-kadai-to Sono-eikyo-hyoka-(Empirical Analysis of the Green Contracts in Competitive Power Procurements by Government Entities-Assessment of the Impacts of 
Environmental Quality Thresholds-)," CRIEPI Research Report No. Y09002, Central Research Institute of Electric Power Industry, Tokyo (in Japanese).

Heckman, J. J. (1976) "The Common Structure of Statistical Models of Truncation, Sample Selection and Limited Dependent Variables and a Simple Estimator for such Models," Annals of Economic \& Social Measurement 5 (4), 475-492.

Heckman, J. J., J. L. Tobias, and E. Vytlacil (2003) "Simple Estimators for Treatment Parameters in a Latent-variable Framework," Review of Economics and Statistics 85 (3), $748-755$.

Kainou, K. (2007) "Denryoku-jiyuka-wa Ikanaru-koka-o Motta-ka (What is the Impact of the Power Market Reforms?)," in: T. Hatta and M. Tanaka (eds.) Kisei-kaikaku-no Keizai-koka-bunseki (Economic Analysis of Regulatory Reforms), Nikkei Publishing, Ch. 1, 1-74 (in Japanese).

Kotz, S., and S. Nadarajah (2004) Multivariate t Distributions and their Applications. Cambridge University Press.

Li, T., and X. Zheng (2009) "Entry and Competition Effects in First-Price Auctions: Theory and Evidence from Procurement Auctions," Review of Economic Studies 76 (4), $1397-1429$.

Maddala, G. S. (1983) Limited-dependent and Qualitative Variables in Econometrics, Cambridge University Press.

Paarsh, H., and H. Hong (2006) An Introduction to the Structural Econometrics of Auction Data, MIT Press.

Spiegelhalter, D. J., N. G. Best, B. P. Carlin, and A. van der Linde (2002) "Bayesian Measures of Model Complexity and Fit," Journal of the Royal Statistical Society Series B 64 (4), 583-639.

Watanabe, T. (2001) "On Sampling the Degree-of-freedom of Student's-t Disturbances," Statistics \& Probability Letters 52, 177-181.

Wooldridge, J. M. (2001) Econometric Analysis of Cross-section and Panel Data, MIT Press. 


\section{Acknowledgements}

This is an extension of our earlier work published in Nihon Keizai Kenkyu (JCER Economic Journal) in 2009. In this study, we elaborate our econometric method by employing a nonparametric approach to examine the same dataset. We are grateful to the Journal for granting us permission to reuse some of the tables and figures appearing in the original article. 


\section{Appendix: Markov Chain Monte Carlo Method for the Estimation of Endogenous Regime-Switching Regression Model}

\section{A.1 Detailed Model Specification}

To separate the effects of load factor on the power charge or the bidding decision from those of other explanatory variables, we rewrite models (1) and (2) as follows.

$$
\begin{aligned}
& d_{i}=1\left\{\mathbf{z}_{i} \gamma+g_{d}\left(l_{i}\right)+\varepsilon_{i} \geq 0\right\} \\
& y_{j, i}=\mathbf{x}_{i} \beta_{j}+g_{j}\left(l_{i}\right)+\eta_{j, i} \quad j=0,1
\end{aligned}
$$

where the variable $l_{i}$ represents the load factor level, and $g_{d}\left(l_{i}\right)$ and $g_{j}\left(l_{i}\right)$ are the effects of the load factor on the dependent variable. The variables $\mathbf{z}_{i}$ and $\mathbf{x}_{i}$ are the other explanatory variables.

We first consider the parametric specification of the load factor curve $g_{j}\left(l_{i}\right)$ in the most general parametric form as follows.

$$
g_{j}\left(l_{i}\right)=\kappa_{j, 1} l_{i}+\kappa_{j, 2} l_{i}^{2}+\kappa_{j, 3} l_{i}^{3}+\kappa_{j, 4} l_{i}^{-1}+\kappa_{j, 5} l_{i}^{-2}=\mathbf{l}_{i}^{\prime} \kappa_{j} \quad j=0,1, d .
$$

With this specification, this standard switching regression model,

$$
\begin{aligned}
& d_{i}=1\left\{\mathbf{z}_{i} \boldsymbol{\gamma}+\mathbf{l}_{i}^{\prime} \boldsymbol{\kappa}_{d}+\varepsilon_{i} \geq 0\right\}=1\left\{\underline{\mathbf{z}}_{i} \underline{\boldsymbol{\gamma}}+\varepsilon_{i} \geq 0\right\}=1\left\{d_{i}^{*} \geq 0\right\}, \\
& y_{j, i}=\mathbf{x}_{i} \boldsymbol{\beta}_{j}+\mathbf{l}_{i}^{\prime} \boldsymbol{\kappa}_{d}+\eta_{j, i}=\underline{\mathbf{x}}_{i} \underline{\boldsymbol{\beta}}_{j}+\eta_{j, i} \quad j=0,1,
\end{aligned}
$$

can be estimated by the same method as Chib (2007). We briefly describe our estimation procedure.

Let $\mathbf{y}_{j}$ and $\mathbf{X}_{j}$ denote the dependent variable vector and the matrix of the explanatory variables in (2') for the competition state $j$; let $\mathbf{d}_{j}^{*}$ and $\mathbf{Z}_{j}$ denote the latent variable vector and the matrix of the explanatory variables in (1') for the subsample under the competition state $j$. Error terms are $\boldsymbol{\varepsilon}_{j}=\mathbf{d}_{j}^{*}-\mathbf{Z}_{j} \underline{\boldsymbol{\gamma}}, \boldsymbol{\eta}_{j}=\mathbf{y}_{j}-\mathbf{X}_{j} \underline{\boldsymbol{\beta}}_{j}$. The vector 
$\lambda_{j}$ consists of the scale mixture variables for the competition state $j$, and the diagonal matrix $\boldsymbol{\Lambda}_{j}$ has $\lambda_{j}$ as its diagonal elements. For the use in the posterior densities, we introduce the following notations.

$$
\begin{aligned}
& \mathbf{y}_{j}^{*}=\mathbf{y}_{j} \otimes\left(\begin{array}{l}
1 \\
0
\end{array}\right)+\mathbf{d}_{j}^{*} \otimes\left(\begin{array}{l}
0 \\
1
\end{array}\right), \\
& \mathbf{X}_{j}^{*}=\left[\left(j \cdot \mathbf{X}_{j},(1-j) \cdot \mathbf{X}_{j}\right) \otimes\left(\begin{array}{l}
1 \\
0
\end{array}\right), \mathbf{Z}_{j} \otimes\left(\begin{array}{l}
1 \\
0
\end{array}\right)\right] .
\end{aligned}
$$

To implement the MCMC method, we set the prior distributions for parameters in the following manner. The prior distribution of $\underline{\boldsymbol{\delta}}=\left(\underline{\boldsymbol{\beta}}_{1}^{\prime}, \underline{\boldsymbol{\beta}}_{0}^{\prime}, \underline{\boldsymbol{\gamma}}^{\prime}\right)^{\prime}$ is an independent multivariate normal distribution with mean $\mathbf{b}$ and variance $\mathbf{B}$ (i.e., $\underline{\boldsymbol{\delta}} \sim N(\mathbf{b}, \mathbf{B}))^{14}$. Reparameterizing $\omega_{j}=\rho_{j} \sigma_{j}$ and $\phi_{j}^{2}=\sigma_{j}^{2}-\omega_{j}^{2}$, the prior distributions are $\phi_{j}^{2} \sim \operatorname{inverseGamma}(r / 2, q / 2)$ and $\omega_{j} \mid \phi_{j}^{2} \sim N\left(m, \phi_{j}^{2} M\right) .{ }^{15}$ Finally, the prior distribution of $v$ is also a gamma distribution: $v \sim \operatorname{Gamma}(\alpha / 2, \zeta / 2) .{ }^{16}$ Since all conditional posteriors but $v$ are explicitly derived in Chib (2007), the Gibbs sampling algorithm can be applied. We sample the conditional posterior of $v$ by the MetropolisHastings acceptance-rejection algorithm proposed by Watanabe (2001). We summarize the sampling procedure as follows.

1. Sample $\left\{\left(\phi_{j}^{2}, \omega_{j}\right)\right\}_{j=0,1}$ given $\underline{\boldsymbol{\delta}}, \mathbf{d}^{*}, \lambda, v$, and $(\mathbf{X}, \mathbf{Z}, \mathbf{y})$.

$$
\phi_{j}^{2} \sim \text { inverse Gamma }\left(\left(r+n_{j}\right) / 2,\left(q+N_{j}\right) / 2\right),
$$

where $N_{j}=\left(\boldsymbol{\eta}_{j}-m \cdot \boldsymbol{\varepsilon}_{j}\right)^{\prime}\left(\boldsymbol{\Lambda}_{j}+M \cdot \boldsymbol{\varepsilon}_{j} \boldsymbol{\varepsilon}_{j}^{\prime}\right)^{-1}\left(\boldsymbol{\eta}_{j}-m \cdot \boldsymbol{\varepsilon}_{j}\right)$, and $n_{j}$ is the length of

14 We set $\mathbf{b}$ as a zero vector and $\mathbf{B}$ as 100 times an identity matrix.

${ }^{15}$ We set $r=4, q=2, m=0$, and $M=10$.

${ }^{16}$ We set $\alpha=\zeta=15$. 
$\mathbf{y}_{j}$

(1-2) $\quad$ Given $\phi_{j}^{2}$, sample $\omega_{j} \mid \phi_{j}^{2} \sim N\left(F_{j}^{-1} G_{j}, \phi_{j}^{2} \cdot F_{j}^{-1}\right)$

where $F_{j}=M^{-1}+\boldsymbol{\varepsilon}_{j}^{\prime} \boldsymbol{\Lambda}_{j} \boldsymbol{\varepsilon}_{j}$, and $G_{j}=m \cdot M^{-1}+\boldsymbol{\eta}_{j}^{\prime} \boldsymbol{\Lambda}_{j} \boldsymbol{\varepsilon}_{j}$.

2. Sample $\underline{\boldsymbol{\delta}} \sim N(\hat{\boldsymbol{\delta}}, \hat{\mathbf{D}})$ given $\left\{\left(\phi_{j}^{2}, \omega_{j}\right)\right\}_{j=0,1}, \mathbf{d}^{*}, \lambda, v$, and $(\mathbf{X}, \mathbf{Z}, \mathbf{y})$, where

$$
\begin{aligned}
& \hat{\boldsymbol{\delta}}=\hat{\mathbf{D}}^{-1}\left\{\mathbf{B}^{-1} \mathbf{b}+\mathbf{X}_{1}^{* \prime}\left(\boldsymbol{\Lambda}_{1} \otimes \boldsymbol{\Omega}_{1}^{-1}\right) \mathbf{y}_{1}^{*}+\mathbf{X}_{0}^{* \prime}\left(\boldsymbol{\Lambda}_{0} \otimes \boldsymbol{\Omega}_{0}^{-1}\right) \mathbf{y}_{0}^{*}\right\}, \\
& \hat{\mathbf{D}}=\left\{\mathbf{B}^{-1}+\mathbf{X}_{1}^{* \prime}\left(\boldsymbol{\Lambda}_{1} \otimes \boldsymbol{\Omega}_{1}^{-1}\right) \mathbf{X}_{1}^{*}+\mathbf{X}_{0}^{* \prime}\left(\boldsymbol{\Lambda}_{0} \otimes \boldsymbol{\Omega}_{0}^{-1}\right) \mathbf{X}_{0}^{*}\right\}^{-1} .
\end{aligned}
$$

3. Sample the latent variables $\mathbf{d}^{*}$ given $\left\{\left(\phi_{j}^{2}, \omega_{j}\right)\right\}_{j=0,1}, \underline{\boldsymbol{\delta}}, \boldsymbol{\lambda}, v$, and $(\mathbf{X}, \mathbf{Z}, \mathbf{y})$ : for the subsample in the competition state $j, \mathbf{d}_{j}^{*}$ is sampled from t-distribution with location parameter $\mathbf{Z}_{j} \underline{\gamma}+\omega_{j} /\left(\omega_{j}^{2}+\phi_{j}^{2}\right) \cdot \boldsymbol{\eta}_{j}$, scale parameters $\phi_{j}^{2} /\left(\omega_{j}^{2}+\phi_{j}^{2}\right), \quad v$ degrees of freedom, and truncated below zero if $j=1$, or above zero if $j=0$.

4. Sample the latent variables $\lambda$ given $\left\{\left(\phi_{j}^{2}, \omega_{j}\right)\right\}_{j=0,1}, \underline{\boldsymbol{\delta}}, \mathbf{d}^{*}, v$, and $(\mathbf{X}, \mathbf{Z}, \mathbf{y})$ : for each $\quad \lambda_{i} \quad, \quad \lambda_{i} \sim \operatorname{gamma}\left((v+2) / 2,\left(v+L_{i}\right) / 2\right) \quad, \quad$ where $L_{i}=\left\{\left(\eta_{j}-\omega_{j} \cdot \varepsilon_{j}\right)^{2}+\phi_{j}^{2} \cdot \varepsilon_{j}^{2}\right\} / \phi_{j}^{2}$

5. Sample $v$ given $\left\{\left(\phi_{j}^{2}, \omega_{j}\right)\right\}_{j=0,1}, \underline{\boldsymbol{\delta}}, \mathbf{d}^{*}, \lambda$, and $(\mathbf{X}, \mathbf{Z}, \mathbf{y})$ : The conditional posterior density of $v$ is given as follows, $\ln f(v)=\frac{n v}{2} \cdot \ln \left(\frac{v}{2}\right)-n \cdot \ln \Gamma\left(\frac{v}{2}\right)+\frac{v-2}{2} \cdot \sum_{i=1}^{n} \ln \lambda_{i}-\frac{v}{2} \cdot \sum_{i=1}^{n} \lambda_{i}+\ln g_{\Gamma}(v ; \alpha / 2, \zeta / 2)$, where $\Gamma(\bullet)$ is gamma function, and $g_{\Gamma}(\bullet ; \alpha / 2, \xi / 2)$ is a gamma density function. We select the mode of the posterior density of $v$, denoted as $v^{*}$. Define the first and the second order derivative of $\ln f(v)$ at $v^{*}$ as $A$ and $B$, and the Taylor expansion of $\ln f(v)$ around $v^{*}$ up to the second order as 
$\ln h(v) \equiv \ln f\left(v^{*}\right)+A\left(v-v^{*}\right)+0.5 B\left(v-v^{*}\right)^{2}$. To compute a candidate of new $v, x$ is generated from the following acceptance-rejection algorithm.

i. $\quad x \sim N\left(v^{*}-A / B,-B^{-1}\right)$

ii. Accept $x$ with probability $f(x) / h(x)$.

The accepted $x$ is a candidate of new $v$. The next step decides whether the current value of $v$ is updated to the candidate $x$ by the Metropolis-Hastings algorithm as described below:

iii. If $f(v) / h(v)<1$ holds, then set $\pi(x, v)=1$.

iv. If $f(v) / h(v)<1$, in addition,

$$
\begin{aligned}
& \text { if } f(x) / h(x)<1 \text {, then set } \pi(x, v)=h(v) / f(v), \\
& \text { if } f(x) / h(x) \geq 1 \text {, then set } \pi(x, v)=\min \{[h(v) f(x)] /[f(v) h(x)], 1\} \text {. }
\end{aligned}
$$

v. Update the current $v$ by $x$ with probability $\pi(x, v)$, or leave $v$ unchanged.

6. Repeat 1 through 5. The posterior mean estimates are calculated by an MCMC run of length 20,000 draws, following a burn-in cycle of 10,000 draws.

\section{A.2 The Estimation Procedure for the Nonparametric Specification}

To explain the nonparametric specification of $g_{j}\left(l_{i}\right)$, some additional notations are needed. Assume that the curve $g_{j}\left(l_{i}\right)$ is evaluated at the p-grid points $\left\{a_{1}, a_{2}, \ldots, a_{p}\right\}$, where $a_{1}\left(a_{p}\right)$ is set to be equal to, or smaller (larger) than the minimum (maximum) value of $l_{i}$. In our estimation, we set the number of grid points to 40 . The lengths between the grid points are denoted as $h_{t}=a_{t}-a_{t-1}, t=2,3, \ldots, p$. For an observation $l_{i}$, the curve $g_{j}\left(l_{i}\right)$ is given by the internally dividing point using the nearest two grid points $a_{k+1}$ and $a_{k}:$ 


$$
g_{j}\left(l_{i}\right)=\frac{a_{k+1}-l_{i}}{a_{k+1}-a_{k}} \cdot g_{j}\left(a_{k}\right)+\frac{l_{i}-a_{k}}{a_{k+1}-a_{k}} \cdot g_{j}\left(a_{k+1}\right) \equiv w_{i}^{(k)} g_{j, k}+w_{i}^{(k+1)} g_{j, k+1} \text {. }
$$

Therefore, we approximate the curve $g_{j}(l)$ by a piecewise linear fitting. If we set all the weight values other than $w_{i}^{(k)}$ and $w_{i}^{(k+1)}$ to be zero and regard $g_{j, k}$ as parameters, then $g_{j}\left(l_{i}\right)$ becomes a linear combination of weights $\overline{\mathbf{w}}_{i}$ and unknown parameters $\overline{\mathbf{g}}_{j}$, where $\overline{\mathbf{w}}_{i}=\left(w_{i}^{(1)}, w_{i}^{(2)}, \ldots, w_{i}^{(p)}\right)$ and $\overline{\mathbf{g}}_{j}=\left(g_{j, 1}, g_{j, 2}, \ldots, g_{j, p}\right)$. Following Chib and Jeliazkov (2006) and Chib et al. (2009), we assume the prior distribution of the grid point values,

$$
\mathbf{g}_{j} \mid \tau_{j}^{2} \sim N\left(\mathbf{H}^{-1} \hat{\mathbf{g}}_{j}, \tau_{j}^{2}\left(\mathbf{H}^{\prime} \mathbf{D}_{g}^{-1} \mathbf{H}\right)^{-1}\right)
$$

where $\mathbf{g}_{j}=\left(g_{j, 2}, g_{j, 3}, \ldots, g_{j, p}\right), g_{j, 1}=0, \quad \mathbf{D}_{g}=\operatorname{diag}\left\{G, h_{3}, h_{4} \ldots, h_{p}\right\}$, and

$$
\mathbf{H}=\left(\begin{array}{cccccccc}
1 & 0 & 0 & \cdots & 0 & 0 & 0 & 0 \\
-\left(1+h_{3} / h_{2}\right) & 1 & 0 & \cdots & 0 & 0 & 0 & 0 \\
h_{4} / h_{3} & -\left(1+h_{4} / h_{3}\right) & 1 & \cdots & 0 & 0 & 0 & 0 \\
\vdots & \vdots & \vdots & \ddots & \vdots & \vdots & \vdots & \vdots \\
0 & 0 & 0 & \cdots & h_{p-1} / h_{p-2} & -\left(1+h_{p-1} / h_{p-2}\right) & 1 & 0 \\
0 & 0 & 0 & \cdots & 0 & h_{p} / h_{p-1} & h_{p} / h_{p-1} & 1
\end{array}\right) .
$$

We set 40 equally-spaced values over the range of load factor observations in our sample for the grid points. Also we set the parameter $\hat{\mathbf{g}}_{j}=0$ and $\mathrm{G}=10$ to equip the load factor curves with sufficient flexibility.

The load factor curve is denoted as $g_{j}\left(l_{i}\right)=\mathbf{w}_{i}^{\prime} \mathbf{g}_{j}$, thus, equations (1) and (2) are

$$
\begin{aligned}
& d_{i}=1\left\{\mathbf{z}_{i} \boldsymbol{\gamma}+\mathbf{w}_{i}^{\prime} \mathbf{g}_{d}+\varepsilon_{i} \geq 0\right\}=1\left\{\overline{\mathbf{z}}_{i} \bar{\gamma}+\varepsilon_{i} \geq 0\right\}=1\left\{d_{i}^{*} \geq 0\right\}, \\
& y_{j, i}=\mathbf{x}_{i} \boldsymbol{\beta}_{j}+\mathbf{w}_{i}^{\prime} \mathbf{g}_{j}+\eta_{j, i}=\overline{\mathbf{x}}_{i} \overline{\boldsymbol{\beta}}_{j}+\eta_{j, i} \quad j=0,1,
\end{aligned}
$$

where $\mathbf{w}_{i}$ is the vector without the first element of $\overline{\mathbf{w}}_{i}$. This is also a standard switching regression model with an additional smoothness parameter $\tau_{j}^{2}$. Therefore, we must modify those two steps in the MCMC algorithm discussed above. The first is that the posterior of $\overline{\boldsymbol{\delta}}=\left(\overline{\boldsymbol{\beta}}_{1}^{\prime}, \overline{\boldsymbol{\beta}}_{0}^{\prime}, \bar{\gamma}\right)^{\prime}$ must reflect (7) in the following manner. 


$$
\hat{\boldsymbol{\delta}}=\left(\begin{array}{c}
\mathbf{b}_{1} \\
\mathbf{H}^{-1} \hat{\mathbf{g}}_{1} \\
\mathbf{b}_{0} \\
\mathbf{H}^{-1} \hat{\mathbf{g}}_{0} \\
\mathbf{b}_{d} \\
\mathbf{H}^{-1} \hat{\mathbf{g}}_{d}
\end{array}\right), \quad \hat{\mathbf{D}}=\left(\begin{array}{llllll}
\mathbf{B}_{1} & & & & & \\
& \tau_{1}^{2}\left(\mathbf{H}^{\prime} \mathbf{D}_{g}^{-1} \mathbf{H}\right)^{-1} & & & \\
& & \mathbf{B}_{0} & & \\
& & & \tau_{0}^{2}\left(\mathbf{H}^{\prime} \mathbf{D}_{g}^{-1} \mathbf{H}\right)^{-1} & & \\
& & & & \mathbf{B}_{d} & \\
& & & & \tau_{d}^{2}\left(\mathbf{H}^{\prime} \mathbf{D}_{g}^{-1} \mathbf{H}\right)^{-1}
\end{array}\right) .
$$

The second modification is inserting the sampling step for the smoothness parameters of the nonparametric curves $\tau_{j}^{2}, j=1,0, d$. When the prior distribution of $\tau_{j}^{2}$ is given as $\tau_{j}^{2} \sim$ inverse $\operatorname{Gamma}\left(\psi_{j} / 2, \xi_{j} / 2\right)$, then the conditional posterior density is derived as inverse $\operatorname{Gamma}\left(\left(\psi_{j}+p-1\right) / 2,\left(\xi_{j}+\Xi_{j}\right) / 2\right) \quad, \quad$ where $\Xi_{j}=\left(\mathbf{g}_{j}-\hat{\mathbf{g}}_{j}\right)^{\prime}\left(\mathbf{H}^{\prime} \mathbf{D}_{g}^{-1} \mathbf{H}\right)\left(\mathbf{g}_{j}-\hat{\mathbf{g}}_{j}\right) .{ }^{17}$ The modification of the MCMC algorithm for this case is completed by inserting the sampling step for $\tau_{j}^{2}, j=1,0, d$, before the sampling step for $\delta$.

Note that the models (1")-(2") have several variants. For example, only the load factor curve in the selection equation $g_{d}\left(l_{i}\right)$ takes a simple parametric form while the others are nonparametrically specified. We compare various models in terms of the marginal likelihood, computed by the method of Chib and Jeliazkov (2005), or the DIC. Table I shows that the most favorable model specification is model 4 equipped with the $\mathrm{t}$-distributed error terms and with the parametric load factor curves for both the selection and the participation equations.

17 We set $\psi_{j}=6$ and $\xi_{j}=0.01$. 
Table I: Results of Model Comparisons

\begin{tabular}{|c|c|c|c|c|}
\hline \multirow{3}{*}{$\begin{array}{l}\text { Log-marginal } \\
\text { likelihood } \\
\text { (std. error) }\end{array}$} & \multirow{3}{*}{ DIC } & \multicolumn{3}{|c|}{ Model specifications } \\
\hline & & \multirow[b]{2}{*}{$\begin{array}{l}\text { Distribution of } \\
\text { error terms }\end{array}$} & \multicolumn{2}{|c|}{ Effects of load factor } \\
\hline & & & $\begin{array}{l}\text { Power Charge } \\
\text { Function: Eq. (2) }\end{array}$ & $\begin{array}{l}\text { PPSs' Bid- } \\
\text { submission } \\
\text { Function: Eq. (1) }\end{array}$ \\
\hline$-886.08(0.05)$ & 1527.1 & & parametric & parametric \\
\hline$-934.52(0.07)$ & 53.3 & & nonparame & etric \\
\hline$-923.58(0.74)$ & 1557.6 & normal & nonparametric & nonparametric \\
\hline$-822.51(0.33)$ & 1401.3 & $\mathrm{t}$ distribution & parametric & parametric \\
\hline$-849.06(0.51)$ & 1421.5 & $\mathrm{t}$ distribution & nonparametric & parametric \\
\hline$-855.06(0.15)$ & 1426.0 & t distribution & nonparametric & nonparametric \\
\hline
\end{tabular}

